\title{
Evaluation of Hearing in Patients With Rheumatoid Arthritis Compared With Controls
}

\author{
Assist. Prof. Zafer Volkan Gökçe, MD¹ - Sidar Öztürk, MD¹ - Ceki Paltura, MD² \\ 1 Department of Orthopaedics and Traumatology, Derindere Hospital, Istanbul, Turkey \\ ORCID NO: 0000-0002-4712-3732 \\ 1 Department of Orthopaedics and Traumatology, Derindere Hospital, Istanbul, Turkey \\ ORCID NO: 0000-0002-3536-204X \\ 2 Department of Otorhinolaryngology, Gaziosmanpasa Taksim Training and Research Hospital, İstanbul, Turkey \\ ORCID NO: 0000-0002-0971-3643
}

\begin{abstract}
Objective: To demonstrate the effects of rheumatoid arthritis (RA) on hearing with audiometric and tympanometric measurements, and to reveal its relationship with the disease in comparison with healthy volunteers.

Methods: The study included 30 RA patients and 30 healthy controls. Demographic findings such as age, height, weight, onset of complaint (year), time elapsed since diagnosis, previous surgery, accompanying systemic disease, drugs used, family history, habits of smoking and alcohol use were questioned for both groups. Tympanometry, pure voice audiometry and otoacoustic Emission tests were performed.
\end{abstract}

Results: The hearing thresholds in the airway conduction in RA group were significantly higher in all frequencies $(0.25-6 \mathrm{kHz})$ than in the control group. When bone con- duction hearing thresholds were compared, RA group was more affected at only $4 \mathrm{kHz}$ and left ear $(p=0.006)$. When air-bone conduction differences (AB-gap) were examined, the differences in the RA group at 0.5, 1 and $4 \mathrm{kHz}$ were statistically significant. When tympanometry and acoustic reflex measurement results were evaluated, there was no statistically significant difference between groups. In the transient OAE test, $3(10 \%)$ patients were in the RA and $2(6.6 \%)$ patients in the control group $(p=0.064)$.

Conclusion: Conductive hearing loss was significantly more frequent in patients with RA than in healthy individuals, whereas bone conduction was affected partially at high frequencies; whereas stapes reflex, compliance and pressure values were not significantly affected.

Keywords: Hearing, sensorineural hearing loss, rheumatoid arthritis.

\section{Introduction}

Rheumatoid arthritis (RA) is one of the most common autoimmune diseases affecting about $1 \%$ of the world population. ${ }^{[1]}$ Although the etiology is not known, genetic, hormonal, immunological disorders, sex, infectious agents, trauma and the etiological roles of stress have been investigated. The most common extra-articular involvement sites in RA are; lung, heart, skin and eyes. In the head-neck region; temporomandibular joint, larynx, cervical spine and audiovestibular system may be affected. ${ }^{[2]}$ The disease
Correspondence: Assist.Prof. Zafer Volkan Gökçe, MD

Department of Orthopaedics and Traumatology, Derindere Hospital, Istanbul, Turkey e-mail: zafervolkangokce@gmail.com

Received: 10.06.2019; Accepted: 24.07.2019
Online available at: www.entupdates.org 
affects the synovial joints symmetrically causing cartilage and bone damage.

Hearing loss in patients with RA is a debatable issue. Its physiopathology has not been fully explained and it has been reported that both conduction type and sensorineural hearing loss (SNHL) is present in patients. RA mostly prefers the synovial diarthrodial joints. Diarthrodial type incudostapedial and inkudomalleolar joints in the middle ear can be affected by RA. ${ }^{[3]}$ While the ankylosis in the joints leads to a decrease in ossicular movements, more importantly its piston effect does not change. It has been reported that SNHL is more common in RA patients (24-60\%) and it is caused by RA influencing the inner ear. ${ }^{[4]} \mathrm{RA}$ may cause auditory neuropathy with mononeuritis multiplex type vasculitis. Autoimmunity may cause destruction of cochlear hair cells or the accumulation of immune deposits in the inner ear. Drugs used in the treatment of RA may affect the inner ear. Some of these drugs are salicylates, other nonsteroidal anti-inflammatory drugs, anti-malarial drugs and cyclosporine. ${ }^{[5]}$ There are also studies suggesting lack of any relationship between hearing loss and RA. ${ }^{[6]}$

In the present study, we aimed to demonstrate the effects of RA on hearing with audiometric and tympanometric measurements, and to reveal its relationship with the disease in comparison with healthy volunteers.

\section{Methods}

Study Design: The approval of the Maltepe University Institutional Review Board was obtained prior to the study. The study included 30 RA patients and 30 healthy controls applied to Orthopedics and Traumatology outpatient clinic between June 2018 and December 2018, and diagnosed according to the 1987 ACR criteria. The control group consisted of healthy individuals without any illness.

Patients with previous and other chronic diseases during the study, hearing loss due to drug use (ototoxic drugs such as aminoglycoside and salicylate), chronic otitis media, retracted tympanic membrane-serous otitis media and those who had middle ear surgery were excluded from both groups.

Outcome Parameters: Demographic findings such as age, height, weight, onset of complaint (year), time elapsed since diagnosis, previous surgery, accompanying systemic disease, drugs used, family history, habits of smoking and alcohol use were questioned for both groups. Tympanometry (Interacustic AZ-26 Denmark 2000), pure voice audiometry (Interacustic AC-33 Denmark 2000) and tic Emission (OAE) (Interacustic ILO 25 Denmark 2002) tests were performed in patients included in the study. Pure tone averages were determined between 250-6.000 $\mathrm{Hz}$ frequencies in all patients. The patients with conductive hearing loss, mixed type hearing loss, and SNHL were detected. Acoustic stapes reflexes (ASR) and tympanograms of the patients were evaluated and ASRs at 500, 1000, 2000 $\mathrm{Hz}$ were evaluated as absent or present. Tympanogram curves were evaluated as type A, B, C, and As. All patients underwent transient $\mathrm{OAE}$ testing. Patients who responded and did not respond to the test at least 3 frequencies were evaluated as "passed "and "failed", respectively.

Statistical Analysis: Statistical analysis of all data was done using the SPSS (Statistical Package for Social Sciences) 21 program. Frequency values, percentages, arithmetic averages and standard deviations of all data were calculated. The Kolmogorov-Smirnov test was used to determine whether the data conformed to normal distribution. Chisquare tests were used to determine the difference between groups. The difference between the data was considered significant if $p$ value was below 0.05 .

\section{Results}

The RA Group included 30 patients (22 females, 8 males) with a mean age of $47.8 \pm 6.9$ years. The Control Group included 30 patients ( 21 females, 9 males) with a mean age of $45.9 \pm 8.1$ years. Both groups did not differ from each other by means of age and gender $(\mathrm{p}=0.644$, and $\mathrm{p}=0.422$, respectively).

When the pure tone audiometry results of the patient and control groups were compared, the hearing thresholds in the airway conduction in RA group were significantly higher in all frequencies $(0.25-6 \mathrm{kHz})$ than in the control group. When bone conduction hearing thresholds were compared, it was found that RA group was more affected at only 4 $\mathrm{kHz}$ and left ear $(\mathrm{p}=0.006)$. When air-bone conduction differences (AB-gap) were examined, the differences in the RA group at $0.5,1$ and $4 \mathrm{kHz}$ were statistically significant. The audiometric measurement results of the patient and control groups and the comparison data between the groups are shown in Table $\mathbf{1 .}$

When tympanometry and acoustic reflex measurement results were evaluated, there was no statistically significant difference between groups $(\mathrm{p}=0.72$ for right ear in tympanometric measurement and $\mathrm{p}=0.64$ for left ear). A comparison of the tympanometry test and acoustic reflex positivity results of the groups is shown in Table 2 . 
Table 1. Analysis of audiogram (dB) by frequency of RA patients and controls (mean $\pm S D$ ).

\begin{tabular}{|c|c|c|c|c|c|}
\hline & & & $\begin{array}{l}\text { RA Group } \\
(n=30)\end{array}$ & $\begin{array}{c}\text { Control Group } \\
(n=30)\end{array}$ & $p$ Value \\
\hline \multirow{14}{*}{ Air conduction (dB) } & & Right & $25.4 \pm 5.9$ & $17.9 \pm 8.1$ & $<0.001$ \\
\hline & 0.25 & Left & $26.4 \pm 5.8$ & $18.1 \pm 8.2$ & $<0.001$ \\
\hline & & Right & $22.2 \pm 6.4$ & $19.2 \pm 5.4$ & $<0.001$ \\
\hline & 0.5 & Left & $23.4 \pm 6.9$ & $19.1 \pm 7.8$ & $<0.001$ \\
\hline & & Right & $20.2 \pm 7.4$ & $16.4 \pm 4.6$ & 0.012 \\
\hline & & Left & $20.8 \pm 5.9$ & $17.2 \pm 4.2$ & 0.004 \\
\hline & & & & & \\
\hline & & Right & $20.4 \pm 8.4$ & $16.8 \pm 4.1$ & 0.024 \\
\hline & & Left & $20.9 \pm 7.2$ & $15.6 \pm 3.9$ & 0.006 \\
\hline & & Right & $26.2 \pm 9.3$ & $16.9 \pm 4$ & $<0.001$ \\
\hline & & Left & $29.2 \pm 11.4$ & $18.8 \pm 4.8$ & $<0.001$ \\
\hline & & Right & $31.8 \pm 11.1$ & $23.0 \pm 7.6$ & $<0.001$ \\
\hline & 6 & & & & \\
\hline & & Left & $33.8 \pm 12.4$ & $24.2 \pm 8$ & $<0.001$ \\
\hline \multirow{10}{*}{ Bone conduction $(\mathrm{dB})$} & & Right & $14.8 \pm 5.7$ & $14.2 \pm 4.1$ & 0.468 \\
\hline & 0.5 & & & & \\
\hline & & Left & $14.9 \pm 6.8$ & $13.6 \pm 4.8$ & 0.384 \\
\hline & & Right & $14.1 \pm 5.8$ & $13.8 \pm 4.2$ & 0.592 \\
\hline & & Left & $13.6 \pm 8.1$ & $13.1 \pm 3.8$ & 0.284 \\
\hline & & & & & \\
\hline & & Right & $13,8 \pm 7.2$ & $12.6 \pm 4.6$ & 0.146 \\
\hline & & Left & $14.8 \pm 7.8$ & $13.1 \pm 3.9$ & 0.124 \\
\hline & & Right & $16.9 \pm 8.4$ & $15.9 \pm 4.2$ & 0.094 \\
\hline & & Left & $18.6 \pm 9.6$ & $13.2 \pm 3.8$ & 0.006 \\
\hline \multirow{10}{*}{ Air-bone gap (dB) } & & Right & $8.6 \pm 5.2$ & $4.4 \pm 3.8$ & $<0.001$ \\
\hline & 0.5 & & & & \\
\hline & & Left & $8,4 \pm 5.1$ & $5.2 \pm 3.9$ & $<0.001$ \\
\hline & & Right & $7.4 \pm 4.8$ & $5.1 \pm 4.0$ & 0.042 \\
\hline & 1 & Left & $7.4 \pm 4.4$ & $5.2 \pm 4.1$ & 0.032 \\
\hline & & & & & \\
\hline & & Right & $7.6 \pm 5.4$ & $4.1 \pm 3.8$ & 0.224 \\
\hline & 2 & Left & $7.2 \pm 4.8$ & $6.5 \pm 4.1$ & 0.246 \\
\hline & & Right & $8.8 \pm 5.9$ & $5.2 \pm 4.4$ & $<0.001$ \\
\hline & & Left & $11.8 \pm 6.4$ & $6.2 \pm 4.2$ & $<0.001$ \\
\hline
\end{tabular}




\begin{tabular}{|c|c|c|c|c|c|}
\hline & & \multicolumn{2}{|c|}{$\begin{array}{l}\text { RA Group } \\
(n=30)\end{array}$} & \multicolumn{2}{|c|}{$\begin{array}{c}\text { Control Group } \\
(n=30)\end{array}$} \\
\hline & & Right* & Left** & Right* & Left ${ }^{* *}$ \\
\hline \multirow{6}{*}{ Tympanometry (\%) } & Type A & 64.5 & 59.9 & 70 & 65 \\
\hline & Type As & 3.5 & 0 & 4 & 0 \\
\hline & Type Ad & 32 & 38.1 & 26 & 35 \\
\hline & Type B & 0 & 2.0 & 0 & 0 \\
\hline & Type C & 0 & 0 & 0 & 0 \\
\hline & Type D & 0 & 0 & 0 & 0 \\
\hline \multicolumn{2}{|c|}{ Acoustic reflex positivity (\%) } & 100 & 100 & 100 & 100 \\
\hline
\end{tabular}

*: for the right ear $p=0,72, * *$ : for the left ear $p=0,64$

In the transient OAE test, $3(10 \%)$ patients were in the RA and $2(6.6 \%)$ patients in the control group $(\mathrm{p}=0.064)$.

\section{Discussion}

Rheumatoid arthritis has been shown to cause both SNHL and conductive hearing loss in patients. In this study, it was shown that conductive hearing loss was significantly more common in patients with RA, whereas bone conduction was affected especially at high frequencies and partially, whereas stapes reflex, compliance and pressure values were not significantly affected.

The prevalence of conductive hearing loss is reported to be between $0.0-17.4 \% .{ }^{[7,8]}$ Conductive hearing loss in RA may be due to impaired movement of the middle ear or deterioration of the ossicles. Colletti et al reported that conductive hearing loss was caused by movement disorder in the ossicular system. ${ }^{[7]}$ Reiter et al reported loss of conductive hearing loss of 0.25 to $0.5 \mathrm{kHz}$ in patients with RA $(30-35 \mathrm{~dB}) \cdot{ }^{[9]}$ The idea that RA may affect the joints of the ossicles was found logical and pathological evidence has been demonstrated by Gussen. ${ }^{[10]}$ It has been suggested that incudostapedial and incudomalleolar joints are replaced by cellular collagenous tissue. Copeman et al reported that conductive hearing loss was associated with disease activity and used the term osteoarthritis. ${ }^{[1]}$

Elwany et al observed movement disorder in the ossicular system in $56 \%$ of the ears of 68 patients with RA. ${ }^{[8]}$ In this study, conductive hearing loss was detected in $1(1.5 \%)$ patient. The prevalence of sensorineural hearing loss in RA is reported to be between $0 \%$ and $60 \%$. It has been report ed that sensorineural hearing loss is due to cochlear changes. [7,9] The finding of the retrocochlear effect of RA was not detected by the majority of the authors, but Magaro found this effect. ${ }^{[12]}$ Kakani et al found mixed type 4 hearing loss in RA patients. ${ }^{[13]}$ Salvinelli et al reported that conductive type and sensorineural hearing loss would be seen in patients with RA. ${ }^{[14]}$ Heyworth et al found a sensorineural hearing loss in $36.4 \%$ of patients with RA; They did not find any evidence that RA affected the ossicular chain. ${ }^{[15]}$ RA was hypothetically thought to cause sensorineural or labyrinthine dysfunction by arthritis or neuropathy. Callejo et al detected a hearing loss in $42.7 \%$ of the patients with RA. ${ }^{[16]}$ Sensorineural hearing loss was detected in $38.6 \%$ of these patients. Ozturk et al detected sensorineural hearing loss, especially at high frequencies, in RA patients. ${ }^{[17]}$ Baradaranfar et al. stated that hearing loss at $8000 \mathrm{~Hz}$ was sensorineural and loss of acoustic reflex was due to the involvement of the middle ear ${ }^{[18]}$ Similar to the literature, our study also showed that conductive type hearing loss was significantly higher in our RA patients and that bone conduction was affected particularly at high frequencies and partially, and as a result both conductive and SNHL were observed. Similar to the literature, in our study; airway hearing thresholds in RA patients were significantly higher in all frequencies than in the control group. Bone pathway hearing thresholds were generally higher than the control group but were not statistically significant.

In their study, in patients with RA without conductive hearing loss, Moffat et al analyzed oto-admittance using tympanograms, and a marked notch at $660 \mathrm{~Hz}$ in $38 \%$ of 
the ears of RA patients, and only in $8 \%$ of the ears in the control group. ${ }^{[19]}$ They associated the notched curve detected in the tympanogram with an increase in ossicular system mobility. In contrast, other authors have found a decrease in the mobility of ossicular system ${ }^{[8,9]}$ Rosenberg et al reported that patients with RA had a similar abnormality in $42 \%$ of the ears of RA patients, and $7 \%$ of the ears in the control group. ${ }^{[20]}$ The resulting result was attributed to the inadequacy of the middle ear conduction system. ${ }^{[14]}$ In their study with multiple frequency tympanometry, Coletti et al, detected an increase in the hardness of the ossicular system in $40 \%$ of the patients with RA. ${ }^{[7]}$ This result may be due to a reduction in the mobility of one or both of the joints or the ankylosis in the ossicle chain. In their study Kakani et al ${ }^{[13]}$ found abnormal tympanograms in $10 \%$ of the patients. All of these tympanograms have been reported to be of As type. ${ }^{[8]}$ This condition was interpreted as decreased compliance and increased stiffness of the tympanoossicular system. In our study; the results of tympanometry of RA patients did not show a significant difference in terms of compliance and pressure values from the control group. In our study, any significant intergroup difference was not detected as for measurements of acoustic reflexes.

Murdin et al found that the majority of RA patients had not undergone Transiently Evoked Otoacoustic Emission (TEOAE) examinations. ${ }^{[21]}$ They thought this might be an indicator of early asymptomatic hearing loss. Ashok et al

\section{References}

1. Smolen JS, Aletaha D, McInnes IB. Rheumatoid arthritis. Lancet 2016;388:2023-38.

2. Angelotti F, Parma A, Cafaro G, Capecchi R, Alunno A, Puxeddu I. One year in review 2017: pathogenesis of rheumatoid arthritis. Clin Exp Rheumatol 2017;35:368-78.

3. Chen R, Schwander M, Barbe MF, Chan MM. Ossicular bone damage and hearing loss in rheumatoid arthritis: a correlated functional and highresolution morphometric study in collagen-1nduced arthritic mice. PLoS One 2016;11:e0164078.

4. Emamifar A, Bjoerndal K, Hansen IM. Is hearing impairment associated with rheumatoid arthritis? A review. Open Rheumatol J 2016;10:26-32.

5. GazeauP, Saraux A, Devauchelle-Pensec V, Cornec D. Long-term efficacy of infliximab in autoimmune sensorineural hearing loss associated with rheumatoid arthritis. Rheumatology 2014;53:1715-6.

6. ÖzkııışM, Kapusuz Z, Günaydın İ, Kubilay U, Pırtı İ, Saydam L. Does rheumatoid arthritis have an effect on audiovestibular tests? Eur Arch Otorhinolaryngol 2014;271:1383-7.

7. Colletti V, Fiorino FG, Bruni L, Biasi D. Middle ear mechanics in subjects with rheumatoid arthritis. Audiology 1997;36:136-46. investigated rheumatoid factor and hearing loss, and found that $27 \%$ of the patients with rheumatoid factor positivity, had not undergone Distortion Product Otoacoustic Emission tests. ${ }^{[22]}$ Dikici et al found a significant decrease in TEOAE at $1.0 / 1.5 / 2.0$ and $3.0 \mathrm{kHz}$ amplitude values, and a significant increase in the ipsilateral stapes reflex at $1.0 \mathrm{kHz}$ thresholds. ${ }^{[23]}$ In the present study, we could not find any significant difference between the two groups in our OAE measurements. The relatively low number of our patients, a single-centered cross-sectional design of our study, lack of long-term follow-up data, and the fact that frequencies above $6 \mathrm{kHz}$ were not evaluated can be considered as limitations of this study.

\section{Conclusions}

In conclusion, this study showed that conductive hearing loss was significantly more frequent in patients with RA than in healthy individuals, whereas bone conduction was affected partially at high frequencies; whereas stapes reflex, compliance and pressure values were not significantly affected. We think it would be beneficial for clinicians following RA patients to consider possible hearing loss.

\section{Acknowledgements}

The authors declare no competing interests. No financial support was received for this paper.
8. Elwany S, el Garf A, Kamel T. Hearing and middle ear function in rheumatoid arthritis. J Rheumatol 1986;13:878-81.

9. Reiter D, Konkle DF, Myers AR, Schimmer B, Sugar JO. Middle ear immittance in rheumatoid arthritis. Arch Otolaryngol 1980;106:114-7.

10. Gussen R. Atypical ossicle joint lesions in rheumatoid arthritis with sicca syndrome (Sjögren syndrome). Arch Otolaryngol 1977;103:284-6.

11. Capeman WS. Rheumatoid oto-arthritis. Br Med J 1963;2:1526-7.

12. Magaro M, Zoli A, Altomonte L, et al. Sensorineural hearing loss in rheumatoid arthritis. Clin Exp Rheumatol 1990;8:487-90.

13. Kakani RS, Mehra YN, Deodhar SD, Mann SB, Mehta S. Audiovestibular functions in rheumatoid arthritis. J Otolaryngol 1990;19:100-2.

14. Salvinelli F, D’Ascanio L, Casale M, Vadacca M, Rigon A, Afeltra A. Auditory pathway in rheumatoid arthritis. A comparative study and surgical perspectives. Acta Otolaryngol 2006;126:32-6.

15. Heyworth T, Liyanage SP. A pilot survey of hearing loss in patients with rheumatoid arthritis. Scand J Rheumatol 1972;1:81-3.

16. García Callejo FJ, Conill Tobías N, Muñoz Fernández N, de Paula Vernetta C, Alonso Castañeira I, Marco Algarra J. (Hearing impairment in patients with rheumatoid arthritis). [Article in Spanish] Acta Otorrinolaringol Esp 2007;58:232-8. 
17. Oztürk A, Yalçin S, Kaygusuz I, Sahin S, Gök U, Karlidağ T, et al. High-frequency hearing loss and middle ear involvement in rheumatoid arthritis. Am J Otolaryngol 2004;25:411-7.

18. Baradaranfar MH, Doosti A. A survey of relationship between rheumatoid arthritis and hearing disorders. Acta Med Iran 2010;48:371-3.

19. Moffat DA, Ramsden RT, Rosenberg JN, Booth JB, Gibson WP. Otoadmittance measurements in patients with rheumatoid arthritis. J Laryngol Otol 1977;91:917-27.

20. Rosenberg JN, Moffat DA, Ramsden RT, Gibson WP, Booth JB. Middle ear function in rheumatoid arthritis. Ann Rheum Dis 1978;37:522-4.
21. Murdin L, Patel S, Walmsley J, Yeoh LH. Hearing difficulties are common in patients with rheumatoid arthritis. Clin Rheumatol 2008;27:63740.

22. Ashok Murthy V, Mohan Kumar J. Rheumatoid factor and hearing loss. Indian J Otolaryngol Head Neck Surg 2012;64:364-5.

23. Dikici O, Muluk NB, Tosun AK, Unlüsoy I. Subjective audiological tests and transient evoked otoacoustic emissions in patients with rheumatoid arthritis: analysis of the factors affecting hearing levels. Eur Arch Otorhinolaryngol 2009;266:1719-26.

This is an open access article distributed under the terms of the Creative Commons Attribution-NonCommercial-NoDerivs 3.0 Unported (CC BY- NC-ND3.0) Licence (http://creativecommons.org/licenses/by-nc-nd/3.0/) which permits unrestricted noncommercial use, distribution, and reproduc- tion in any medium, provided the original work is properly cited.

Please cite this article as: Gökçe ZF, Öztürk S, Paltura C. Evaluation of Hearing in Patients With Rheumatoid Arthritis Compared With Controls. ENT Updates 2019;9(2): 122-127 